\title{
An ambidextrous approach to practice-based innovation for social product development: lessons from a Dutch company
}

\author{
Maria Carmela Annosi \\ Department of Management Studies \\ Wageningen University, Wageningen, NL \\ Giacomo Marzi \\ Lincoln International Business School \\ University of Lincoln, Lincoln, UK \\ Francesco Ciampi \\ DISEI - Dipartimento di Scienze per l'Economia e l'Impresa, \\ Università degli Studi di Firenze, Firenze, IT \\ Riccardo Rialti \\ DISEI - Dipartimento di Scienze per l'Economia e l'Impresa, \\ Università degli Studi di Firenze, Firenze, IT
}

Published on IEEE Transactions on Engineering Management

FULL TEXT (DOI): $\underline{\text { https://doi.org/10.1109/TEM.2020.2977976 }}$

\begin{abstract}
In the face of increasing competition, an organization's capacity to acquire knowledge from the outside has become fundamental for new product development. Pertinent extant literature has stressed how an organization should practice social product development, allowing for the inclusion of all types of stakeholders in idea generation, selection, validation, and commercialization.

This study investigates how organizations can acquire, maintain, and use different sources of knowledge via ambidextrous habits of exploitation and exploration to sustain social product development. A case study based on 27 semi-structured interviews and field observations at a leading, large-size, Dutch food-service company has been carried out. The findings illustrate the organizational processes and mechanisms that the company has adopted to address and combine practice- and research-based knowledge, as well as the main barriers limiting the accumulation and usage of this knowledge inside organizational boundaries.
\end{abstract}




\section{Managerial Relevance Statement}

This study sheds light on the different practices that companies use effectively to acquire and manage knowledge produced in collaboration with customers, as well as sustain social product development. We investigate how a company can acquire and use such knowledge effectively to explore the creation of new products and update products that have been offered already. This study represents a practical example of how a large company updates its routines and internal practices to foster creation of practice-based knowledge, then uses it synergistically with researchbased knowledge. We also show how a large company can adopt several social product development practices. Our findings show that both social product development and the joint use of research-based and practice-based knowledge can exert a significant influence on the company's ambidexterity and, ultimately, crucially impact its competitive advantage. Finally, we discuss how some barriers could reduce the flow of knowledge within the company, such as the lack of internal and external cross-boundary collaboration in the delivery of services, an inadequate consistency between the different organizational routines, the lack of reflection in action, and unfocused roles and fuzzy awareness about the organization's direction. 